\title{
Bioactivity, biocompatibility and antimicrobial properties of a chitosan-mineral composite for periodontal tissue regeneration
}

\author{
Andrew Paul Hurt', Arun Kumar Kotha ${ }^{1}$, Vivek Trivedi ${ }^{1}$ and Nichola Jayne Coleman ${ }^{1 *}$ \\ ${ }^{1}$ School of Science, University of Greenwich, ME4 4TB, Chatham Maritime, Kent, United Kingdom \\ *nj_coleman@yahoo.co.uk
}

\begin{abstract}
A composite membrane of the polymer, chitosan, and the silver-exchanged mineral phase, tobermorite, was prepared by solvent casting and characterised by scanning electron microscopy and Fourier transform infrared spectroscopy. The in vitro bioactivity, cytocompatibility and antimicrobial activity of the composite were evaluated with respect to its potential application as a guided tissue regeneration (GTR) membrane. The in vitro bioactivity was verified by the formation of hydroxyapatite on the surface of the membrane in simulated body fluid and its cytocompatibility was established using MG63 human osteosarcoma cells. The presence of silver ions conferred significant antimicrobial activity against $S$. aureus, $P$. aeruginos $a$ and $E$. coli. The findings of this investigation have indicated that the chitosansilver-tobermorite composite is a prospective candidate for GTR applications.
\end{abstract}

Keywords: chitosan, tobermorite, silver, bioactive, antimicrobial, guided tissue regeneration, periodontal repair.

\section{Introduction}

Periodontitis - inflammation and progressive destruction of the tooth attachment apparatus - is one of the most widespread infectious diseases in the world ${ }^{[1]}$. This disease is initiated by the accumulation of bacterial plaque biofilms causing gingivitis, which, if left untreated, leads to the detachment of the epithelial tissue, disconnection of the periodontal ligament (PDL) and the loss of cementum and alveolar bone ${ }^{[1-3]}$. Traditional treatment of this condition involves the removal of plaque and calculus from the root surface without an attempt to restore the surrounding tissues. The rapidly growing epithelial cells subsequently propagate alongside the tooth root and prevent the re-establishment of the PDL and alveolar bone. Thus the treated periodontal tissues possess a long junctional epithelium and are vulnerable to further bacterial infection and recurrent episodes of periodontitis.

The use of biocompatible membranes for the guided tissue regeneration (GTR) of compromised periodontal structures is an increasingly popular option for the treatment of periodontitis ${ }^{[1-4]}$. The GTR approach involves the placement of a membrane to exclude the fast-growing soft tissues from the exposed root surface in order to enable the more slow-growing PDL and hard tissues to regenerate ${ }^{[1-4]}$. These GTR barriers can be fabricated from either non-resorbable materials (e.g. PTFE) which require surgical removal after service, or resorbable materials (e.g. poly(urethane)) which will biodegrade in situ. In both cases, the principal cause of failure of GTR membranes is bacterial biofilm formation leading to infection; hence, improvements in the design of GTR membranes to incorporate antimicrobial components are now required ${ }^{[1]}$.

Chitosan is the partially N-deacetylated derivative of chitin, a naturally abundant structural polysaccharide obtained from the shells of crustaceans ${ }^{[5-7]}$. It is non-toxic,

biodegradable, biocompatible, bioactive, non-antigenic, antimicrobial and finds current biomedical application in wound dressings and medical textiles ${ }^{[5-9]}$. It is a basic linear co-polymer of glucosamine and $\mathrm{N}$-acetylglucosamine whose structure resembles that of bone extracellular matrix (ECM) ${ }^{[10,11]}$. In comparison with traditional treatment, the application of bioresorbable chitosan-based GTR membranes has been shown to successfully promote the regeneration of the tooth attachment tissues in canine models ${ }^{[12-14]}$.

Despite its many advantages, chitosan in GTR applications is not sufficiently bioactive to stimulate optimum bone tissue regeneration. It is also prone to bacterial biofilm formation. Previous studies have indicated that blending chitosan with finely divided bioactive and antibacterial phases, such as bioactive glasses, calcium phosphate minerals and silver nanoparticles can enhance bone tissue regeneration and reduce bacterial biofilm formation ${ }^{[1,15,16]}$.

Tobermorite, $\mathrm{Ca}_{5} \mathrm{Si}_{6} \mathrm{O}_{16}(\mathrm{OH})_{2} \cdot 4 \mathrm{H}_{2} \mathrm{O}$, is a bioactive calcium silicate phase that can be ion-exchanged with antibacterial silver ions ${ }^{[17,18]}$. The layered structure of tobermorite resembles the calcium silicate hydrate gel phases of the endodontic cements, MTA and Biodentine, which are reported to stimulate the regeneration of cementum and bones tissues ${ }^{[19-21]}$. A recent in vitro study has demonstrated that the incorporation of synthetic tobermorite into chitosan films enhances both bioactivity and biocompatibility ${ }^{[22]}$.

In this work, a candidate composite GTR membrane of chitosan and silver-exchanged tobermorite has been prepared by solvent-casting and characterised by scanning electron microscopy (SEM) and Fourier transform infrared spectroscopy (FTIR). The bioactivity of the composite membrane was evaluated in vitro and its biocompatibility was assessed using human MG63 osteosarcoma cells. An inhibition zone 
assay was used to determine the antimicrobial activity of the membrane against Staphylococcus aureus, Pseudomonas aeruginosa and Escherichia coli.

\section{Materials and Methods}

\subsection{Preparation and characterisation}

Chitosan (50-190 kDa molecular weight, 75-85\% deacetylated) and all other reagents were purchased from Sigma-Aldrich, UK, and used without further modification. Triplicate samples of silver-exchanged tobermorite were prepared characterised by powder X-ray diffraction (XRD) analysis and X-ray fluorescence spectroscopy (XRF), as described in reference ${ }^{[18]}$. The Bragg peaks of the silverexchanged tobermorite were identified and indexed using JCPDS file 45-1480. The formulae of the original tobermorite and $\mathrm{Ag}$-tobermorite used in this study were $\mathrm{Ca}_{4.55} \mathrm{Na}_{0.44} \mathrm{Si}_{6.00} \mathrm{O}_{16.77} \cdot 6.4 \mathrm{H}_{2} \mathrm{O}$ and $\mathrm{Ca}_{4.06} \mathrm{Na}_{0.04} \mathrm{Ag}_{0.92} \mathrm{Si}_{6.00}$ $\mathrm{O}_{16.54} \cdot 11.9 \mathrm{H}_{2} \mathrm{O}$, respectively.

Chitosan-silver-tobermorite composite membranes (CTAg) were prepared at a chitosan:Ag-tobermorite mass ratio of $10: 7$ by solvent casting. $2 \%(\mathrm{w} / \mathrm{v})$ solutions of chitosan were prepared in triplicate by dissolving $0.6 \mathrm{~g}$ of the polymer in $30 \mathrm{~cm}^{3}$ of $2 \%(\mathrm{v} / \mathrm{v})$ acetic acid solution. $0.42 \mathrm{~g}$ of Ag-tobermorite were then added and the mixtures were stirred for 5 hours, cast onto polycarbonate plates and dried in air at $60{ }^{\circ} \mathrm{C}$ to constant mass to produce the CTAg membranes. Control membranes (labelled CT) for the antimicrobial inhibition zone assay were prepared similarly with the original tobermorite samples.

The CTAg membranes were characterised by FTIR using a Perkin Elmer Paragon spectrometer and by SEM using uncoated samples attached to carbon tabs on an Hitachi SU8030 scanning electron microscope. Secondary electron images were obtained at an accelerating voltage of $1 \mathrm{kV}$.

\subsection{In vitro bioactivity analysis of CTAg membrane}

Simulated body fluid (SBF) was prepared according to the method described by Kokubo and Takadama ${ }^{[23]} .16 \mathrm{~cm}^{3}$ sections of CTAg membrane were placed in $20 \mathrm{~cm}^{3}$ of SBF solution in sealed polypropylene containers at $37^{\circ} \mathrm{C}$ for periods of 3, 7 and 14 days. The $\mathrm{pH}$ of the SBF solution was measured using a Jenway $3150 \mathrm{pH}$ meter and the concentrations of calcium, phosphorus and silicon were monitored by inductively coupled plasma analysis using a Perkin Elmer Optima 4300 DV spectrophotometer and multi-element standards. The recovered CTAg membranes were rinsed with deionised water, dried in air at $37^{\circ} \mathrm{C}$ for $24 \mathrm{~h}$ and analysed by FTIR. Each analysis was carried out in triplicate.

\subsection{Kirby-Bauer inhibition zone assay of CTAg and CT membranes}

The antimicrobial properties of the CTAg and CT membranes were assessed using the Kirby-Bauer inhibition zone method against Staphylococcus aureus NCIMB 9518, Escherichia coli NCIMB 9132 and Pseudomonas aeruginosa NCIMB 8628. Overnight cultures of each bacterium were spread on nutrient agar plates. Individual $8 \mathrm{~mm}$ discs of the
CTAg and CT membranes were placed in the centre of each spread plate. Each assay was conducted in quadruplicate. The plates were examined for clear zones after incubation at $37^{\circ} \mathrm{C}$ for 24 hours. The final population densities of the plates spread with $S$. aureus, E. coli and P. aeruginosa were approximately $1.0 \times 10^{9}, 5.9 \times 10^{8}$, and $5.9 \times 10^{9}$ colony forming units per plate.

\subsection{In vitro biocompatibility of CTAg membrane}

The in vitro biocompatibility of the CTAg membrane was evaluated using MG63 human osteosarcoma cells (ECACC code: 86051601$)$ as described in reference ${ }^{[22]}$. In triplicate, either 0,1 or 4 CTAg membrane strips (1 $\mathrm{mm} \mathrm{x} 4 \mathrm{~mm}$ ) were incubated with the MG63 cells for 24 hours and cell viability was established using an MTT (3-(4,5-Dimethyl-2thiazolyl)-2,5-diphenyl-2H-tetrazolium bromide) assay ${ }^{[22]}$. Data were subjected to a one-tailed t-test at $(n-2)$ degrees of freedom and $\mathrm{P}=0.05$.

\section{Results and Discussion}

\subsection{Materials characterisation}

The powder XRD pattern of Ag-tobermorite is shown in Figure 1a and closely resembles those of other tobermorites reported in the literature ${ }^{[18,24]}$. Minor traces of calcite, $\mathrm{CaCO}_{3}$, (denoted by asterisks) are also present and commonly arise from atmospheric carbonation during the hydrothermal preparation of tobermorites. These data confirm that silver ions were exchanged for calcium and sodium ions within the tobermorite phase without any notable structural disruption of the lattice and that no silver-bearing precipitates were formed.

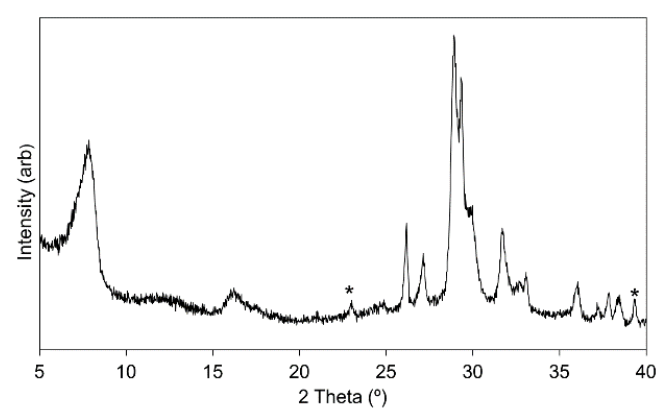

(a)

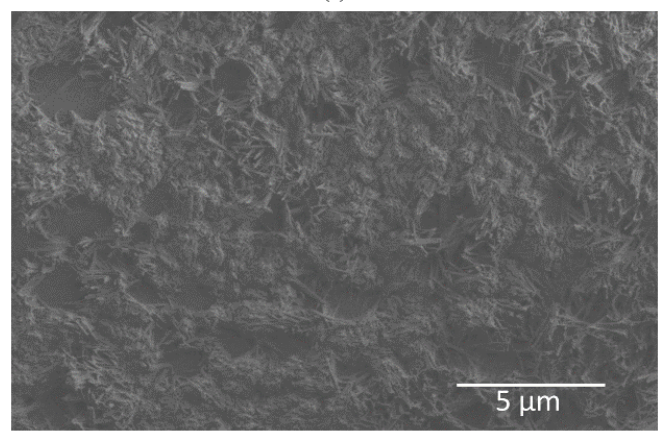

(b)

Figure 1. (a) XRD pattern of silver-exchanged tobermorite, (b) SEM image of CTAg composite membrane. 
An SEM micrograph of the CTAg composite is presented in Figure $1 \mathrm{~b}$ and shows that the membrane's topography is highly textured on a sub-micron scale and that the surface is characterised by fibrous tobermorite particles dispersed throughout a network of felted chitosan strands.

The FTIR spectrum of Ag-tobermorite is presented in Figure 2a. The bands at $c a .960 \mathrm{~cm}^{-1}$ and $675 \mathrm{~cm}^{-1}$ arise from various $\mathrm{Si}-\mathrm{O}$ stretching modes and $\mathrm{Si}-\mathrm{O}-\mathrm{Si}$ bending vibrations, respectively ${ }^{[16]}$. O-H vibrations of silanol bonds and interlayer water molecules give rise to the broad bands at 1630 and $3450 \mathrm{~cm}^{-1}$.

The FTIR spectrum of chitosan is shown in Figure $2 \mathrm{~b}$. The broad signal at $~ 3460 \mathrm{~cm}^{-1}$ is attributed to N-H and O-H stretching modes which overlap in this region; and the bands at 1650 and $1570 \mathrm{~cm}^{-1}$ arise from amide $\mathrm{I} \mathrm{C}=\mathrm{O}$ stretching and amide II N-H bending vibrations, respectively ${ }^{[25]}$. C-H stretching vibrations occur at $2960-2965 \mathrm{~cm}^{-1}$ and $\mathrm{C}-\mathrm{H}$ bending modes give rise to the bands at $1420-1430 \mathrm{~cm}^{-1}$ and $1365 \mathrm{~cm}^{-1}$. Various C-O-C stretching frequencies occur in the range $1160-1060 \mathrm{~cm}^{-1}$ and the band at $1295 \mathrm{~cm}^{-1}$ is attributed to $\mathrm{C}-\mathrm{O}-\mathrm{H}$ stretching vibrations. The FTIR spectrum of the solvent-cast CTAg composite membrane, shown in Figure 2c, is essentially the sum of the individual spectra of Ag-tobermorite and chitosan with no significant shifts in the characteristic bands of either material. However, the bands at 1365,1295 and $1160 \mathrm{~cm}^{-1}$ (which arise from aliphatic $\mathrm{C}-\mathrm{H}, \mathrm{C}-\mathrm{O}-\mathrm{H}$ and $\mathrm{C}-\mathrm{O}-\mathrm{C}$ groups, respectively) are less distinct and appear as poorly resolved shoulders in the spectrum of the composite owing to the overlap of the $\mathrm{Si}-\mathrm{O}$ band of the tobermorite. The diminished intensity of the $\mathrm{C}-\mathrm{O}-\mathrm{H}$ band could also indicate an interaction between this group and the tobermorite lattice.

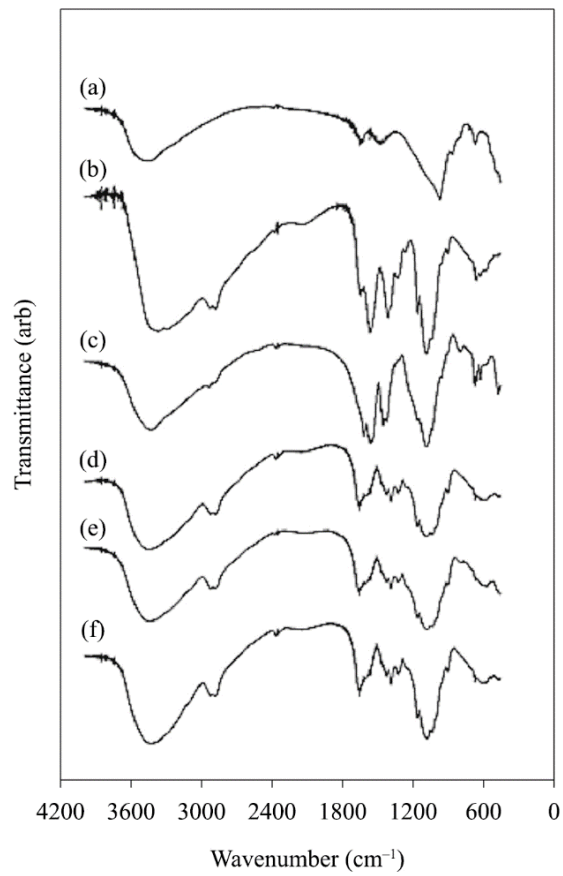

Figure 2. FTIR spectra of (a) Ag-tobermorite, (b) chitosan, (c) CTAg membrane and CTAg membrane after immersion in SBF for (d) 3 days, (e) 7 days and (f) 14 days.

\subsection{In vitro bioactivity of the CTAg membrane}

The in vitro formation of a layer of substituted hydroxyapatite, $\mathrm{Ca}_{10}\left(\mathrm{PO}_{4}\right)_{6}(\mathrm{OH})_{2}$, $(\mathrm{HA})$ on the surface of a material placed in SBF solution provides an indication of its bioactivity (i.e. the ability of the material to bond with living bone tissue $)^{[23]}$.

The formation of an HA layer on the surface of the CTAg membrane was monitored by FTIR spectroscopy and ICP analysis. The FTIR spectra of CTAg following exposure to SBF for 3, 7 and 14 days are shown in Figures 2(d), (e) and (f), respectively, and the corresponding concentrations of calcium, phosphorus and silicon species in the solution are presented in Figure 3.

Characteristic phosphate $\mathrm{P}-\mathrm{O}$ bending modes of $\mathrm{HA}$ are noted at $570-610 \mathrm{~cm}^{-1}$ in the FTIR spectrum of the CTAg membrane after 3 days' residence in SBF (Figure 2d). The additional broadening of the combination band at $c a$. $1075 \mathrm{~cm}^{-1}$ arises from the contribution of P-O stretching modes in the $1000-1220 \mathrm{~cm}^{-1}$ range and is further evidence for the formation of $\mathrm{HA}^{[20]}$. The corresponding removal of phosphate ions and release of silicate and calcium ions are plotted in Figure 3. These data indicate that the SBF solution is essentially depleted of phosphate ions within 14 days as the HA precipitation process nears completion. The silicate ion concentration of SBF rises from zero to $66 \mathrm{ppm}$ within the first 3 days which corresponds with the dissolution of approximately $43 \%$ of the Ag-tobermorite lattice. The rate of dissolution of the Ag-tobermorite lattice then slows significantly, which is likely to be attributed to the solubility limit of silicate species in this closed system. The degradation of the Ag-tobermorite matrix also causes a steady increase in the supernatant concentration of calcium ions and a comparatively slow release of silver ions. Silver is only detected in solution at 7 and 14 days at concentrations of 0.5 and $4.6 \mathrm{ppm}$, respectively, which correspond to the respective release of 0.6 and $1.1 \%$ of the total mass of silver present in the membrane. The delayed release of silver ions into the SBF solution during the degradation of the Ag-tobermorite lattice may arise from ion exchange interactions with the functional groups of chitosan.

In spite of the steady release of calcium ions throughout the investigation, the $\mathrm{pH}$ of the SBF solution varied little about the original value of 7.45 (Figure 3). This indicates that the alkaline dissolution products of the Ag-tobermorite

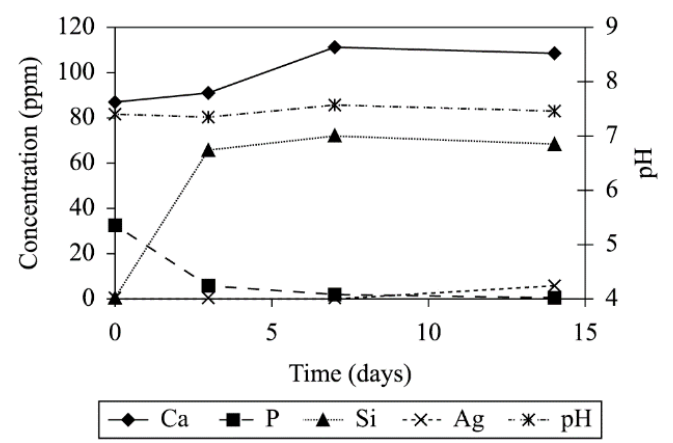

Figure 3. Concentrations of $\mathrm{P}, \mathrm{Ca}, \mathrm{Si}$ and $\mathrm{Ag}$ in $\mathrm{SBF}$ and corresponding $\mathrm{pH}$ as functions of residence time. 
lattice are buffered by the acidic degradation products of the chitosan.

\subsection{Antibacterial properties of CTAg and CT membranes}

The results of the antibacterial inhibition zone assays using S. aureus, P. aeruginosa and E. coli are listed in Table 1. Distinct clear zones were noted around the silver-bearing CTAg composite membranes in contact with all three microorganisms and in each case the bacteria were observed to readily colonise the surfaces of the control CT discs.

The microbiota of the dental biofilm in periodontitis is highly complex. In addition to the characteristic anaerobic Gram-negative oral microorganisms, the 'non-oral' pathogenic bacteria S. aureus, P. aeruginos a and E. coli are commonly detected within the subgingival biofilm of patients with chronic and aggressive periodontitis ${ }^{[2,27]}$. These bacteria are highly prevalent in bone and dental implant-centred infections and are among the principal pathogens associated with osteomyelitis ${ }^{[28,29]}$.

The eradication of S. aureus, P. aeruginosa and E. coli in the presence of implanted biomaterials is particularly challenging owing to their biofilm formation and superior antimicrobial resistance ${ }^{[29]}$. Once bacterial adhesion has occurred on a biomaterial implant surface, the microorganisms secrete an exopolysaccharide layer that protects them from the host's immune response and from subsequent antibiotic therapy. The host tissue cells are then unlikely to be able to displace the persistent biofilm and the implant will require surgical revision.

One strategy to promote host tissue integration over bacterial biofilm formation on implantable biomaterials is the incorporation of antibiotic components ${ }^{[29]}$. In this respect, silver salts, nanoparticles and complexes have been incorporated into a range of wound-dressings and implantable biomedical devices to exploit the broad-spectrum antimicrobial properties of this metal ${ }^{[18]}$.

This research has indicated that the silver-free CT membranes readily supported colonies of $S$. aureus, P. aeruginosa and E. coli at concentrations of $1.0 \times 10^{9}$, $5.9 \times 10^{9}$, and $5.9 \times 10^{8}$ colony forming units per plate, respectively. Conversely, marked inhibitory effects were noted for each microorganism in the presence of the silver-bearing CTAg membranes. Similar prophylaxis against microbial colonisation by $S$. aureus and E. coli has also been reported for composites comprising chitosan and a commercial silver-exchanged zeolite (Ag-Ion) which are intended as antimicrobial food packaging materials ${ }^{[30]}$.

Table 1. Inhibition zone data for CTAg and CT membranes.

\begin{tabular}{lcc}
\hline \multicolumn{1}{c}{ Bacterium } & CTAg & CT control \\
\hline $\begin{array}{l}\text { S. aureus } \\
\text { Zone of inhibition (mm) }\end{array}$ & $0.81 \pm 0.13$ & 0 \\
$\begin{array}{l}\text { P. aeruginosa } \\
\text { Zone of inhibition (mm) }\end{array}$ & $1.44 \pm 0.12$ & 0 \\
E. coli & & \\
Zone of inhibition (mm) & $1.07 \pm 0.13$ & 0 \\
\hline
\end{tabular}

\subsection{In vitro biocompatibility of CTAg membrane}

It is essential that a bioactive GTR membrane is biocompatible with bone tissue. In this respect, human osteosarcoma cells provide a model for the initial in vitro cytotoxicity appraisal of candidate biomaterials for bone tissue regeneration. The indirect cytotoxicity of the CTAg membrane towards MG63 human osteosarcoma cells was evaluated using an MTT assay. This method is derived from the ability of viable cells to reduce the tetrazolium salt of MTT into formazan which is then monitored colorimetrically. The cell viability data for cultures in contact with increasing quantities of CTAg membrane are compared with those of the control (which consisted of cells and media only) in Figure 4. These data indicate that there is no significant loss of cell viability for the cultures in contact with 1 and 4 CTAg membrane strips compared with the control $(\mathrm{P}=0.05)$.

In a similar study, the in vitro viability of human osteosarcoma cells was maintained when exposed to a porous chitosan-hydroxyapatite tissue scaffold embedded with silver nanoparticles ${ }^{[16]}$. Conversely, marked cytotoxic effects on MG63 osteosarcoma cells were observed for a composite coating comprising chitosan, Bioglass ${ }^{\circledR}$ and silver nanoparticles ${ }^{[3]}$. Other research has indicated that the dosage and chemical form in which silver is presented (i.e. as ions, complexes, elemental powder or nanoparticles) impacts upon its biocompatibility with respect to mammalian cells $^{[32]}$. In this case, the dosage and form of silver within the CTAg composite membrane is able to confer antimicrobial activity without compromising in vitro biocompatibility with respect to osteosarcoma cells.

\subsection{CTAg as a GTR membrane}

Extensive clinical research has indicated that the GTR membrane-assisted regeneration of damaged periodontal tissues is favoured over traditional treatment approaches for periodontitis. The principal functions of the GTR membrane are to maintain an appropriate volume into which the compromised PDL and alveolar bone tissues can repopulate and to exclude invasion from the more fast-growing gingival and epithelial tissues. A further, desirable property of the GTR membrane would be an ability to stimulate and enhance the regeneration of the damaged tissues; and an additional asset would be the ability of the material to control bacterial activity at the wound site. This latter property is especially significant, as the damaged periodontal tissue is in contact with the external environment of the oral cavity and is at a high risk of infection during the healing process.

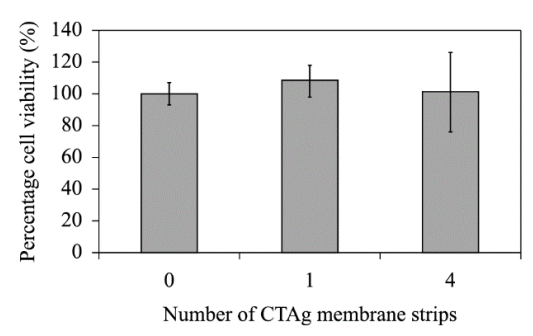

Figure 4. Viability of MG63 human osteosarcoma cells in contact with CTAg composite membrane strips. 
The principal disadvantages of chitosan in GTR applications are that its bioactivity and antimicrobial properties are insufficient and that its acidic dissolution products stimulate inflammatory reactions that inhibit healing ${ }^{[1,25]}$. This study confirms that the CTAg membrane exhibits in vitro bioactivity and that the tobermorite lattice degrades on contact with SBF to release calcium, silicate, silver and hydroxide ions. The basic calcium and hydroxide ions buffer the acidic breakdown products of the chitosan and reduce deviations from the normal physiological $\mathrm{pH}$ of 7.45. Also, the dissolved silicate and calcium ions are both potent chemical signals for osteoblast activity and directed bone cell growth ${ }^{[1,33,34]}$.

In addition to the chemical environment, local topography also regulates the adhesion, expression and growth of osteocytes. Mineralised alveolar bone, cementum and bone ECM possess micron and sub-micron scale textures that favour the attachment and proliferation of bone tissue cells. In this respect, the sub-micron scale roughness of the CTAg membrane and the release of calcium and silicate ions from the tobermorite lattice are all anticipated to contribute to its therapeutic potential with respect to the regeneration of compromised alveolar bone.

The incorporation of silver cations in the composite membrane contributes significantly to its antimicrobial activity against both Gram-positive (S. aureus) and Gramnegative (P. aeruginos $a$ and $E$. coli) bacteria with no observed compromise in cytocompatibility. The very slow release of silver ions from the CTAg membrane is also considered advantageous, as this is likely to provide sustained microbial resistance to bacterial biofilm formation.

\section{Conclusions}

A textured polymer-mineral composite membrane has been prepared by solvent casting a mixture of chitosan and silver-bearing tobermorite. The composite membrane exhibited in vitro bioactivity in simulated body fluid and its cytocompatibility was confirmed using MG63 human osteosarcoma cells via MTT assay. The acidic degradation products of the chitosan polymer were buffered by the alkaline dissolution products of the tobermorite lattice and the slow release of sliver ions significantly enhanced the antimicrobial activity of the membrane against $S$. aureus, $P$. aeruginosa and $E$. coli. The results of this investigation have indicated that the chitosan-silver-tobermorite composite is a prospective candidate for GTR applications.

\section{References}

1. Shimauchi, H., Nemoto, E., Ishihata, H., \& Shimomura, M. (2013). Possible functional scaffolds for periodontal regeneration. Japanese Dental Science Review, 49(4), 118-130. http://dx.doi. org/10.1016/j.jdsr.2013.05.001.

2. Xu, C., Lei, C., Meng, L., Wang, C., \& Song, Y. (2012). Chitosan as a barrier membrane material in periodontal tissue regeneration. Journal of Biomedical Materials Research. Part B, Applied Biomaterials, 100B(5), 1435-1443. http://dx.doi. org/10.1002/jbm.b.32662. PMid:22287502.

3. Chinta, D. P., Katakam, P., Murthy, V. S. N., \& Newton, M. J. (2013). Formulation and in-vitro evaluation of moxifloxacin loaded crosslinked chitosan films for the treatment of periodontitis. Journal of Pharmacy Research, 7(6), 483-490. http://dx.doi.org/10.1016/j.jopr.2013.06.019.

4. Sowmya, S., Bumgardener, J. D., Chennazhi, K. P., Nair, S. V., \& Jayakumar, R. (2013). Role of nanostructured biopolymers and bioceramics in enamel, dentin and periodontal tissue regeneration. Progress in Polymer Science, 38(10-11), 17481772. http://dx.doi.org/10.1016/j.progpolymsci.2013.05.005.

5. Anitha, A., Sowmya, S., Sudheesh Kumar, P. T., Deepthi, S., Prasad Chennazhi, K., Ehrlich, H., Tsurkan, M., \& Jayakumar, R. (2014). Chitin and chitosan in selected biomedical applications. Progress in Polymer Science, 39(9), 1644-1667. http://dx.doi. org/10.1016/j.progpolymsci.2014.02.008.

6. Jiang, T., Deng, M., James, R., Nair, L. S., \& Laurencin, C. T. (2014). Micro- and nanofabrication of chitosan structures for regenerative engineering. Acta Biomaterialia, 10(4), 1632-1645. http://dx.doi.org/10.1016/j.actbio.2013.07.003. PMid:23851172.

7. Croisier, F., \& Jérôme, C. (2013). Chitosan-based biomaterials for tissue engineering. European Polymer Journal, 49(4), 780-792. http://dx.doi.org/10.1016/j.eurpolymj.2012.12.009.

8. Goy, R. C., Britto, D., \& Assis, O. B. G. (2009). A review of the antimicrobial activity of chitosan. Polimeros: Ciência e Tecnologia, 19(3), 241-247. http://dx.doi.org/10.1590/S010414282009000300013.

9. Fernandes, L. L., Resende, C. X., Tavares, D. S., Soares, G. A., Castro, L. O., \& Granjeiro, J. M. (2011). Cytocompatibility of chitosan and collagen-chitosan scaffolds for tissue engineering. Polímeros: Ciência e Tecnologia, 21(1), 1-6. http://dx.doi. org/10.1590/S0104-14282011005000008.

10. Battistella, E., Varoni, E., Cochis, A., Palazzo, B., \& Rimondini, L. (2011). Degradable polymers may improve dental practice. Journal of Applied Biomaterials \& Functional Materials, 9(3), 223-231. http://dx.doi.org/10.5301/JABB.2011.8867. PMid:22139754.

11. Thien, D. V. H., Hsiao, S. W., Ho, M. H., Li, C. H., \& Shih, J. L. (2013). Electrospun chitosan/hydroxyapatite nanofibers for bone tissue engineering. Journal of Materials Science, 48(4), 1640-1645. http://dx.doi.org/10.1007/s10853-012-6921-1.

12. Yeo, Y. J., Jeon, D. W., Kim, C. S., Choi, S. H., Cho, K. S., Lee, Y. K., \& Kim, C. K. (2005). Effects of chitosan nonwoven membrane on periodontal healing of surgically created onewall intrabony defects in beagle dogs. Journal of Biomedical Materials Research. Part B, Applied Biomaterials, 72B(1), 86-93. http://dx.doi.org/10.1002/jbm.b.30121. PMid:15389496.

13. Li, X., Wang, X., Zhao, T., Gao, B., Miao, Y., Zhang, D., \& Dong, Y. (2014). Guided bone regeneration using chitosan-collagen membranes in dog dehiscence-type defect model. Journal of Oral and Maxillofacial Surgery, 72(2), 304.e1-304.e14. http:// dx.doi.org/10.1016/j.joms.2013.09.042. PMid:24438600.

14. Ji, Q. X., Deng, J., Xing, X. M., Yuan, C. Q., Yu, X. B., Xu, Q. C., \& Yue, J. (2010). Biocompatibility of a chitosan-based injectable thermosensitive hydrogel and its effects on dog periodontal tissue regeneration. Carbohydrate Polymers, 82(4), 1153-1160. http://dx.doi.org/10.1016/j.carbpol.2010.06.045.

15. Caridade, S. G., Merino, E. G., Alves, N. M., \& Mano, J. F. (2012). Bioactivity and viscoelastic characterization of chitosan/ bioglass ${ }^{\circledR}$ composite membranes. Macromolecular Bioscience, 12(8), 1106-1113. http://dx.doi.org/10.1002/mabi.201200036. PMid:22707301.

16. Saravanan, S., Nethala, S., Pattnaik, S., Tripathi, A., Moorthi, A., \& Selvamurugan, N. (2011). Preparation, characterization and antimicrobial activity of a bio-composite scaffold containing chitosan/nano-hydroxyapatite/nano-silver for bone tissue engineering. International Journal of Biological Macromolecules, 49(2), 188-193. http://dx.doi.org/10.1016/j. ijbiomac.2011.04.010. PMid:21549747. 
17. Lin, K., Chang, J., \& Cheng, R. (2007). In vitro hydroxyapatite forming ability and dissolution of tobermorite nanofibers. Acta Biomaterialia, 3(2), 271-276. http://dx.doi.org/10.1016/j. actbio.2006.11.003. PMid:17234465.

18. Coleman, N. J. (2009). Aspects of the in vitro bioactivity and antimicrobial properties of $\mathrm{Ag}(+)$ - and $\mathrm{Zn}(2+)$-exchanged 11 A tobermorites. Journal of Materials Science. Materials in Medicine, 20(6), 1347-1355. http://dx.doi.org/10.1007/ s10856-009-3698-0. PMid:19214715.

19. Baek, S.-H., Plenk, H., Jr., \& Kim, S. (2005). Periapical tissue responses and cementum regeneration with amalgam, SuperEBA, and MTA as root-end filling materials. Journal of Endodontics, 31(6), 444-449. http://dx.doi.org/10.1097/01. don.0000148145.81366.a5. PMid:15917684.

20. Katsamakis, S., Slot, D. E., Van der Sluis, L. W. M., \& Van der Weijden, F. (2013). Histological responses of the periodontium to MTA: a systematic review. Journal of Clinical Periodontology, 40(4), 334-344. http://dx.doi.org/10.1111/ jcpe.12058. PMid:23405962.

21. Darvell, B. W., \& Wu, R. C. T. (2011). "MTA"-an Hydraulic Silicate Cement: review update and setting reaction. Dental Materials, 27(5), 407-422. http://dx.doi.org/10.1016/j. dental.2011.02.001. PMid:21353694.

22. Hurt, A. P., Getti, G., \& Coleman, N. J. (2014). Bioactivity and biocompatibility of a chitosan-tobermorite composite membrane for guided tissue regeneration. International Journal of Biological Macromolecules, 64, 11-16. http:// dx.doi.org/10.1016/j.ijbiomac.2013.11.020. PMid:24296410.

23. Kokubo, T., \& Takadama, H. (2006). How useful is SBF in predicting in vivo bone bioactivity? Biomaterials, 27(15), 29072915. http://dx.doi.org/10.1016/j.biomaterials.2006.01.017. PMid:16448693.

24. Grangeon, S., Claret, F., Linard, Y., \& Chiaberge, C. (2013). $\mathrm{X}$-ray diffraction: a powerful tool to probe and understand the structure of nanocrystalline calcium silicate hydrates. Acta Crystallographica. Section B, Structural Crystallography and Crystal Chemistry, B69(Pt 5), 465-473. http://dx.doi. org/10.1107/S2052519213021155. PMid:24056355.

25. Lee, E.-J., Shin, D.-S., Kim, H.-E., Kim, H.-W., Koh, Y.-H., \& Jang, J.-H. (2009). Membrane of hybrid chitosan-silica xerogel for guided bone regeneration. Biomaterials, 30(5), 743-750. http://dx.doi.org/10.1016/j.biomaterials.2008.10.025. PMid: 19027950.

26. Souto, R., Andrade, A. F. B., Uzeda, M., \& Colombo, A. P. V. (2006). Prevalence of "non-oral" pathogenic bacteria in subgingival biofilm of subjects with chronic periodontitis. Brazilian Journal of Microbiology, 37(3), 208-215. http:// dx.doi.org/10.1590/S1517-83822006000300002.
27. Silva-Boghossian, C. M., do Souto, R. M., Luiz, R. R., \& Colombo, A. P. V. (2011). Association of red complex, A. actinomycetemcomitans and non-oral bacteria with periodontal diseases. Archives of Oral Biology, 56(9), 899-906. http://dx.doi. org/10.1016/j.archoralbio.2011.02.009. PMid:21397893.

28. Pye, A. D., Lockhart, D. E. A., Dawson, M. P., Murray, C. A., \& Smith, A. J. (2009). A review of dental implants and infection. The Journal of Hospital Infection, 72(2), 104-110. http://dx.doi.org/10.1016/j.jhin.2009.02.010. PMid:19329223.

29. Ribeiro, M., Monteiro, F. J., \& Ferraz, M. P. (2012). Infection of orthopedic implants with emphasis on bacterial adhesion process and techniques used in studying bacterial-material interactions. Biomatter, 2(4), 176-194. http://dx.doi.org/10.4161/ biom.22905. PMid:23507884.

30. Rhim, J.-W., Hong, S.-I., Park, H.-M., \& Ng, P. K. W. (2006). Preparation and characterization of chitosan-based nanocomposite films with antimicrobial activity. Journal of Agricultural and Food Chemistry, 54(16), 5814-5822. http:// dx.doi.org/10.1021/jf060658h. PMid:16881682.

31. Pishbin, F., Mouriño, V., Gilchrist, J. B., McComb, D. W., Kreppel, S., Salih, V., Ryan, M. P., \& Boccaccini, A. R. (2013). Single-step electrochemical deposition of antimicrobial orthopaedic coatings based on a bioactive glass/chitosan/ nano-silver composite system. Acta Biomaterialia, 9(7), 7469-7479. http://dx.doi.org/10.1016/j.actbio.2013.03.006. PMid:23511807.

32. Hardes, J., Streitburger, A., Ahrens, H., Nusselt, T., Gebert, C., Winkelmann, W., Battmann, A., \& Gosheger, G. (2007). The influence of elementary silver versus titanium on osteoblasts behaviour in vitro using human osteosarcoma cell lines. Sarcoma. 2007 (Article ID 26539), 1-5. http://dx.doi. org/10.1155/2007/26539.

33. Han, P. P., Wu, C. T., \& Xiao, Y. (2013). The effect of silicate ions on proliferation, osteogenic differentiation and cell signalling pathways (WNT and $\mathrm{SHH}$ ) of bone marrow stromal cells. Biomaterials Science, 1(4), 379-392. http://dx.doi. org/10.1039/C2BM00108J.

34. Arcos, D., \& Vallet-Regí, M. (2010). Sol-gel silica-based biomaterials and bone tissue regeneration. Acta Biomaterialia, 6(8), 2874-2888. http://dx.doi.org/10.1016/j.actbio.2010.02.012. PMid:20152946.

Received: July 11, 2014 Revised: Jan. 17, 2015 Accepted: Jan. 23, 2015 